\title{
TÍCH HỢP ÚNG DỤNG ALES - GIS TRONG ĐÁNH GIÁ THÍCH NGHI ĐẤT NÔNG NGHIỆP HỖ TRỌ QUY HOẠCH SỬ DỤNG ĐẤT CẤP XÃ - TRƯỜNG HỢP ĐIỂN HİNH Ở GIA LAI
}

\author{
Nguyễn Ninh Hải ${ }^{1}$, Nguyễn Tuấn Anh ${ }^{1}$, Nguyễn Thị Như Hương ${ }^{2}$, \\ Bạch Quang Dũng ${ }^{3}$, Nguyễn Minh Kỳ ${ }^{1^{*}}$
}

Tóm tắt: Nghiên cưu trình bày kết quả tích hợp ưng dụng phần mềm ALES - GIS trong đánh giá thích nghi đất nông nghiệp phục vu lập quy hoạch sủ dụng đất cấp xã - truờng hợp điển hình xã Ia Dreh, huyện Krông Pa, tỉnh Gia Lai. Nghiên cưu thu thập các số liệu về điều kiện tụ nhiên, kinh tế - xã hội, môi trương thông qua khảo sát nông hộ và đánh giá nhanh có sụ tham gia của cộng đồng (PRA). Phwơng pháp đánh giá thích nghi đất đai theo Tổ chức Nông lưong thế giới (FAO) được sử dụng để đánh giá sụ phù hợ đất đai về kinh tế - xã hội cấp xã, hướng đến sư dụng đất bền vũng. Kết quả cho thấy với các đặc tính đất đai thành lập được 52 đơn vị đất đai (LUMs) chuyên biệt cho 10 kiểu sủ dụng đất (lúa nước; lúa rẫy; đậu đỗ; mỳ; ngô; mè; điều; cây ăn quả; mía; thuốc lá), được tổng hợp thành 18 vùng thich nghi. Trên co sở thích nghi đất đai về điều kiện tụ nhiên, kinh tế và mức độ tác động của yếu tố xã hội, môi trương, các mô hình sử dụng đất theo hướng bền vũng được đề xuất. Qua đó, làm co sở cho việc lập quy hoạch sư dụng đất đai hợp lý, hiệu quả, đáp úng sụ phát triển bền vĩng ở địa phưong.

Từ khóa: Thích nghi đất đai, ALES - GIS, Ia Dreh, Krông Pa, quy hoạch sủ dụng đất, môi truờng.

Ban Biên tập nhận bài: 17/03/2020 ～Ngày phản biện xong: 20/04/2020 Ngày đăng bài: 25/04/2020

\section{1. Đặt vấn đề}

Phương pháp đánh giá đất đai tự nhiên có xem xét yếu tố kinh tế đã được đề ra khá sớm [1]. Năm 1993, Tổ chức Nông lương thế giới (FAO) phát triển phương pháp đánh giá đất đai cho quản lý sử dụng đất bền vững, quan tâm đến các lĩnh vực kinh tế, xã hội, môi trường [2]. Đánh giá đất đai là bài toán phân tích đánh giá đa tiêu chuẩn cung cấp cho người ra quyết định các mức độ quan trọng khác nhau của các tiêu chuẩn do đó kết quả đánh giá còn mang tính chủ quan [3]. Để khắc phục hạn chế này và ứng dụng tri thức của các chuyên gia trong nhiều lĩnh vực, phần mềm đánh giá đất tự động (ALES - Automatic Land Evaluation System) ra đời và kết hợp với công nghệ Hệ thống thông tin địa lý (GIS -

${ }^{1}$ Trưòng Đại học Nông Lâm TP. Hồ Chí Minh ${ }^{2}$ Truoòng Trung hoc phổ thông Pleiku, Gia Lai ${ }^{3}$ Tổng cuc Khí tương Thủy văn

Email:nmky@hcmuaf.edu.vn
Georaphic Information System) có khả năng phân tích không gian, xây dựng cơ sở dữ liệu đất đai để hạn chế tính chủ quan của con người trong việc xác định mức độ thích hợp các loại hình sử dụng đất [4]. Quá trình tích hợp ALES - GIS trên thế giới và các địa phương khác nhau ở nước ta được thực hiện khá nhiều [3, 5-10].

Hiện nay, quá trình sản xuất nông nghiệp trên địa bàn huyện Krông Pa nói chung và xã Ia Dreh đang làm suy giảm nguồn tài nguyên đất đai qua quá trình thâm canh, tăng vụ [11]. Để định hướng phát triển sản xuất nông nghiệp của xã theo hướng bền vững thì vấn đề quan trọng nhằm đánh giá lại tiềm năng đất đai [12]. Qua đó, tiềm năng đất đai sẽ cung cấp những luận cứ cơ sở khoa học giúp các nhà quản lý định hướng lập quy hoạch sử dụng đất theo hướng bền vững. Từ đó tạo ra thế cân bằng trong sản xuất nông nghiệp và sự kết hợp hài hòa giữa kinh nghiệm thực tế của người dân với cơ sở khoa học góp 
phần gia tăng hiệu quả sử dụng đất, nâng cao đời sống và thu nhập người dân. Tuy nhiên, đối với xã Ia Dreh, huyện Krông Pa nói riêng và tỉnh Gia Lai nói chung chưa có nhiều nghiên cứu ứng dụng trong lĩnh vực này. Vì thế nghiên cứu "Tích hợp ứng dụng ALES - GIS trong đánh giá thích nghi đất nông nghiệp hỗ trợ quy hoạch sử dụng đất cấp xã - Trường hợp điển hình ở Gia Lai” theo hướng sử dụng đất bền vững là yêu cầu cấp bách góp thêm cơ sở khoa học và thực tiễn làm mô hình, bài học kinh nghiệm trong công tác đánh giá đất đai lập quy hoạch trên địa bàn tỉnh Gia Lai. Mục tiêu nghiên cứu nhằm xây dựng mô hình tích hợp phần mềm ALES và GIS trong đánh giá thích nghi đất đai theo phương pháp của FAO; vận dụng kết quả mô hình để phục vụ cho việc lập quy hoạch sử dụng và quản lý nguồn tài nguyên đất - trường hợp điển hình xã Ia Dreh huyện Krông Pa, tỉnh Gia Lai.

\section{Phương pháp nghiên cứu}

\subsection{Phương pháp thu thập số liệu}

Nghiên cứu đã thu thập các số liệu thứ cấp về hiện trạng sử dụng đất, tình hình sản xuất nông nghiệp, điều kiện tự nhiên, kinh tế xã hội và môi trường xã Ia Dreh năm 2018. Số liệu được tổng hợp từ các nguồn như: Phòng Nông nghiệp \& Phát triển nông thôn huyện Krông $\mathrm{Pa}, 2018$; Phòng Tài nguyên \& Môi trường huyện Krông Pa, 2018. Các bản đồ chuyên đề hiện trạng sử dụng đất, bản đồ địa hình, bản đồ thổ nhưỡng, bản đồ khí tượng thủy văn, bản đồ hành chính tỷ lệ 1:10.000 được thu thập tại Sở Tài nguyên \& Môi trường tỉnh Gia Lai, 2018.

\subsection{Phwơng pháp chuyên gia và đánh giá nhanh có sụ tham gia của cộng đồng PRA}

Các số liệu thu thập được tổng hợp và kiểm chứng bằng cách khảo sát nông hộ (đánh giá nhanh có sự tham gia của cộng đồng PRA về các kiểu sử dụng đất chính). Ngoài ra, khảo sát chuyên sâu về các vấn đề liên quan đến sử dụng đất, thích nghi đất đai và quy hoạch sử dụng đất đối với cán bộ quản lý và chuyên gia. Các thông tin được đánh giá gồm điều kiện tự nhiên, kinh tế - xã hội - môi trường, những thuận lợi và khó khăn trong quá trình canh tác nông nghiệp. Cụ thể, đối với điều kiện tự nhiên chủ yếu tập trung nội dung cơ sở dữ liệu tài nguyên đất như loại đất, thành phần, độ dốc,... Những vấn đề kinh tế- xã hội và môi trường bao gồm thực trạng hiệu quả hoạt động sản xuất nông nghiệp, các biểu hiện liên quan đến yếu tố thời tiết ở địa phương. Nội dung đánh giá thuận lợi và khó khăn trong quá trình canh tác nông nghiệp lồng ghép tham vấn sâu về các kiểu sử dụng đất và lựa chọn các loại hình sử dụng đất điển hình. Qua đó, hỗ trợ các lựa chọn sử dụng đất trong tương lai dựa trên yếu tố chính sách, thị trường và môi trường sinh thái.

\subsection{Phương pháp bản đồ, GIS và xử lý thống $k \hat{e}$}

Các bản đồ đơn tính được thực hiện bằng phương pháp khảo sát thực địa nhằm khoanh vẽ contour về điều kiện thủy văn, khí hậu trong điều kiện hiện tại. Số liệu sau kiểm chứng được tổng hợp và xử lý thống kê, vẽ biểu đồ phân tích, so sánh và đánh giá về điều kiện sản xuất, mức độ quan trọng của từng yếu tố tác động đến các mô hình canh tác. Nghiên cứu sử dụng máy định vị toàn cầu GPS khảo sát thực địa; phần mềm Micro Station V7, Mapinfo V11 biên tập, chỉnh sửa bản đồ hiện trạng nền cơ sở dữ liệu; phần mềm ArcView V10 chồng xếp, phân tích thuộc tính, đánh giá dữ liệu và thành lập các bản đồ chuyên đề tỷ lệ 1:10.000 như phân vùng thích nghi đất, định hướng sử dụng đất tương lai, v.v..; ALES V4.65 để xác định mức độ thích hợp các loại hình sử dụng đất [4]. Các số liệu thống kê được phân tích, đánh giá và xử lý bằng phần mềm M. Excel 2013.

\subsection{Quy trình tích hợp mô hình ALES và} GIS

GIS là công cụ ứng dụng hữu ích trong việc cung cấp hỗ trợ ra quyết định tốt nhất để thu hẹp khoảng cách giữa các yêu cầu và thực tế. Công nghệ GIS tích hợp các hoạt động cơ sở dữ liệu phổ biến như phân tích truy vấn và thống kê với các lợi ích phân tích địa lý và trực quan. Điểm mạnh GIS là khả năng phân tích đồng thời dữ liệu không gian và dữ liệu thuộc tính, trong đó chức năng chồng lớp (overlay) là một trong 
những chức năng quan trọng [13].

Trong khi, phần mềm ứng dụng ALES bản thân nó không thể biểu diễn kết quả lên bản đồ. ALES được thiết kế như một công cụ cho đánh giá đất đai chuyên nghiệp [14]. Tuy nhiên nó có thể phân tích các thuộc tính của bản đồ đơn vị đất đai (ĐVĐĐ: LMUs) được xây dựng phù hợp với cơ sở dữ liệu của ALES [6]. Đánh giá đất là quá trình đánh giá hiệu quả khi được sử dụng cho các mục đích cụ thể. Do đó, nó là phương pháp quan trọng để hỗ trợ quy hoạch và phát triển nông thôn. Từ kinh nghiệm thực tế cho thấy sự thành công của khung $\mathrm{FAO}[1]$ và các hướng dẫn tiếp theo để áp dụng trong các loại hình sử dụng đất khác nhau [14]. Cụ thể, mô hình tích hợp ALES - GIS đánh giá đất gồm các bước thực hiện như Hình 1.

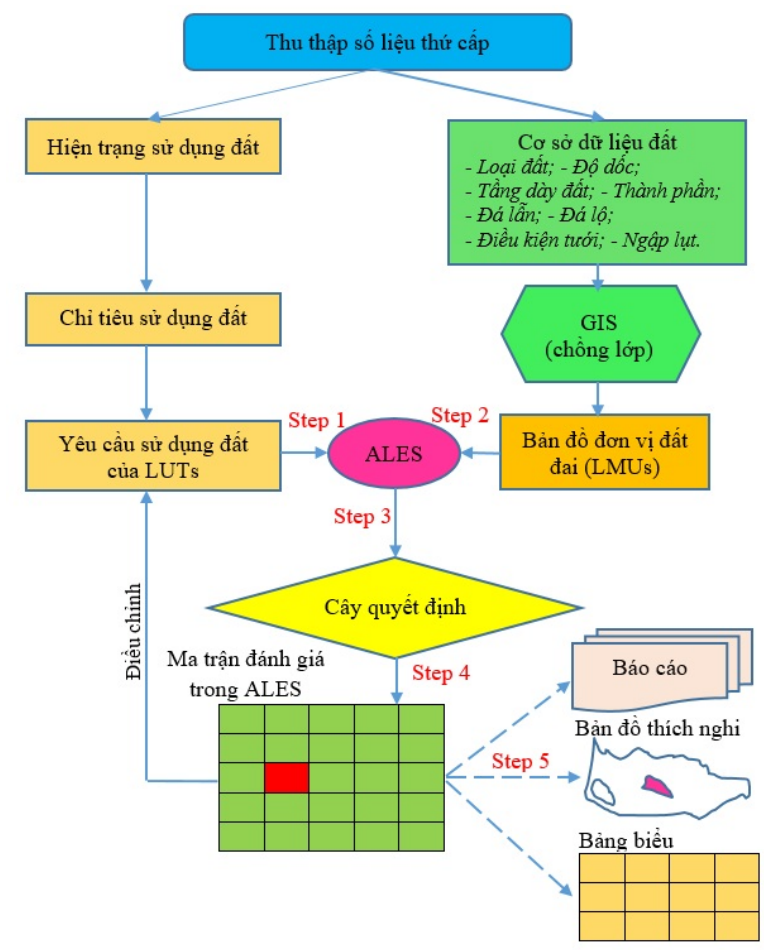

Hình 1. Mô hình tich hơp GIS - ALES đánh giá thich nghi đất đai

Bước 1: Nghiên cứu nhập các yêu cầu sử dụng đất vào ALES.

Bước 2: Đọc dữ liệu (Import data) về tính chất đất đai từ bản đồ ĐVĐĐ (đã được xây dựng trong GIS).

Bước 3: Xây dựng cây quyết định (trong ALES) nhằm xác định các mức hệ số của chất lượng đất đai từ các giá trị đặc trưng đất đai, xác định các năng suất cân đối dự kiến của sản phẩm và phân lớp thích hợp vật lý từ các giá trị của chất lượng đất đai. Đây là các khóa đa chiều phân cấp trong đó các lá của cây quyết định là kết quả như xếp hạng yếu tố đơn chất lượng đất (mức độ nghiêm trọng) và các nút bên trong (điểm nhánh) của cây là các tiêu chí quyết định như giá trị đặc trưng của đất [14].

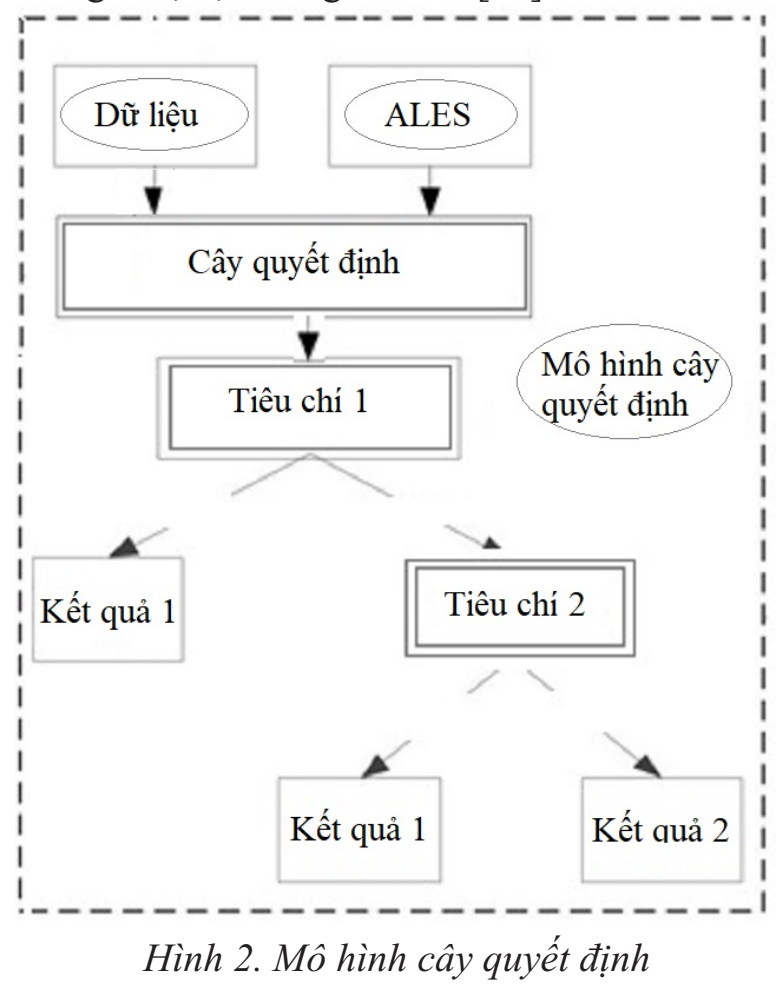

Bước 4: Đánh giá đất đai (trong ALES) bởi ma trận kết quả, kiểm tra kết quả nếu (i)_không phù hợp thì điều chỉnh lại yêu cầu sử dụng đất, nếu (ii)_đúng thì thực hiện bước 5 (B5).

Bước 5: Xuất (Transfer) kết quả đánh giá đất đai sang GIS và thể hiện lên bản đồ thích nghi để biểu diễn về đánh giá đất. Mức độ thích nghi đất đai được phân chia thành 4 cấp [1]: Rất thích nghi (S1), thích nghi trung bình (S2), ít thích nghi (S3) và không thích nghi $(\mathrm{N})$. Ngoài ra, khi thay đổi các thuộc tính bản đồ ĐVĐĐ trong GIS thì mô hình sẽ tự động cập nhật các thuộc tính thay đổi từ GIS và đánh giá để đưa ra kết quả phù hợp và xuất sang GIS để thể hiện bản đồ thích nghi. 


\section{Kết quả nghiên cứu và thảo luận}

\subsection{Hiện trạng sử dụng đất nông nghiệp}

Kết quả thống kê đất đai năm 2018 xã Ia Dreh có tổng diện tích đất tự nhiên là 13349 ha. Trong đó, diện tích đất nông nghiệp gồm đất sản xuất nông nghiệp; đất lâm nghiệp; đất nuôi trồng thủy sản; và đất nông nghiệp khác chiếm tỷ lệ $95,0 \%$ (12718,06 ha) diện tích đất tự nhiên. Diện tích đất phi nông nghiệp là 513,66 ha (chiếm 4,0\%), bao gồm các loại đất ở; đất chuyên dùng; đất cơ sở tôn giáo; đất cơ sở tín ngưỡng; đất nghĩa trang, nghĩa địa; đất sông, ngòi, kênh, rạch, suối; đất có mặt nước chuyên dùng; và đất phi nông nghiệp khác. Diện tích đất chưa sử dụng gồm đất bằng chưa sử dụng; đất đồi núi chưa sử dụng; núi đá không có rừng cây là 117,28 ha, chiếm 1,0\% (Hình 3).

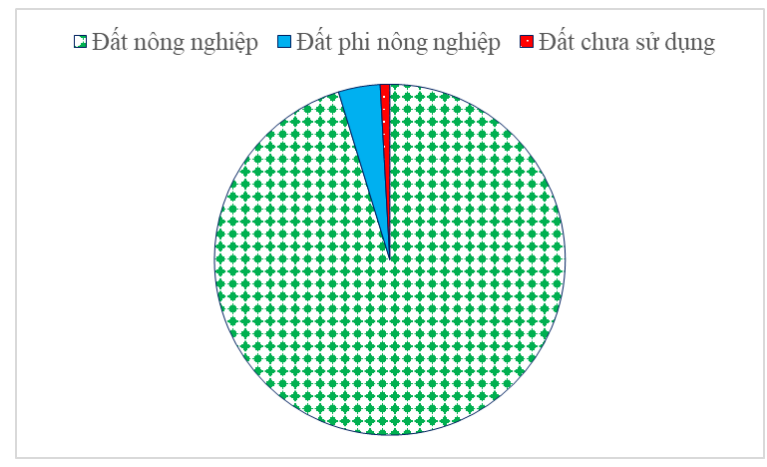

Hình 3. Hiện trạng đất đai năm 2018 xã Ia Dreh

Kết quả tổng hợp hiện trạng sử dụng đất nông nghiệp xã Ia Dreh cho thấy diện tích đất trồng lúa là 946,46 ha, chủ yếu là đất trồng lúa 1 vụ (158,0 ha) và lúa nương rẫy (788,46 ha). Trong khi, diện tích đất trồng cây hàng năm khác (bao gồm các loại rau màu, đậu đỗ, mỳ...) là 2543 ha và là diện tích đất chiếm ưu thế trong diện tích đất sản xuất nông nghiệp; diện tích đất trồng cây lâu năm, cây ăn quả là 613,47 ha (chiếm 61,63\%); diện tích đất lâm nghiệp là 8615,13 ha (Hình 4).

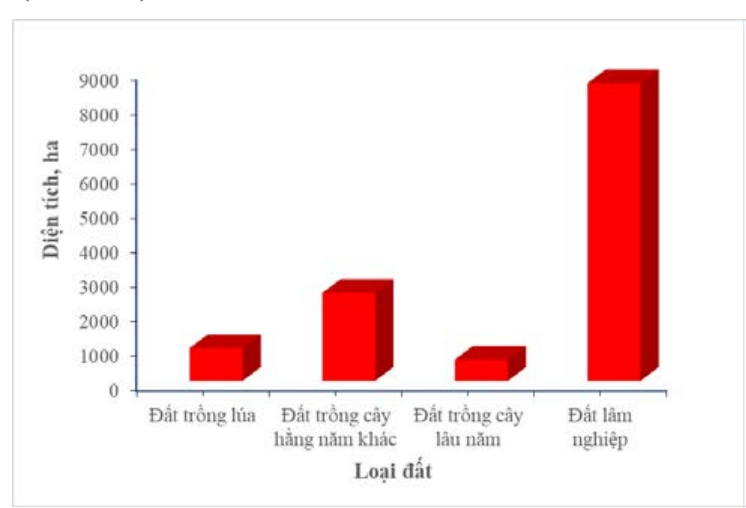

Hình 4. Hiện trạng đất nông nghiệp 2018 ơ Ia Dreh

\subsection{Bản đồ đơn vị đất đai}

Bản đồ đất đai là các lớp dữ liệu chìa khóa quan trọng để phát triển mô hình, đánh giá hiện trạng và chất lượng đất [15]. Đơn vị bản đồ đất đai là một vùng hay một vạt đất, trong đó có sự đồng nhất tương đối của các yếu tố tự nhiên và có sự phân biệt của một hoặc nhiều yếu tố tự nhiên so với các vùng lân cận [1]. Mỗi một LMUs có chất lượng riêng và nó thích hợp với các loại hình sử dụng đất nhất định. Chỉ tiêu xây dựng và kết quả phân vùng thích nghi đất đai xã Ia Dreh, huyện Krông Pa được thể hiện trong Bảng 1 và Hình 5 .

Nghiên cứu ứng dụng hệ thống thông tin địa lý (GIS) xác định các ĐVĐĐ và tích hợp với phần mềm đánh giá đất tự động (ALES) để xác định mức độ thích hợp của các loại sử dụng đất. Bản đồ ĐVĐĐ và phân vùng thích nghi khu vực Ia Dreh, huyện Krông Pa được xây dựng bằng phương pháp tích hợp các bản đồ chuyên đề của 8 nhóm chỉ tiêu trên. 
Bảng 1. Chỉ tiêu xây dụng bản đồ đơn vị đất đai xã Ia Dreh

\begin{tabular}{|c|c|c|c|c|c|c|c|}
\hline $\mathrm{TT}$ & $\begin{array}{l}\text { Phân } \\
\text { cấp }\end{array}$ & $\begin{array}{c}\text { Ký } \\
\text { hiệu }\end{array}$ & Nội dung & $\mathrm{TT}$ & Phân cấp & $\begin{array}{c}\text { Ký } \\
\text { hiệu }\end{array}$ & Nội dung \\
\hline \multirow{14}{*}{$\begin{array}{l}\text { I. Loại đất } \\
\text { (G) }\end{array}$} & \multirow{14}{*}{12 cấp } & 1 & $\mathrm{~Pb}$ & \multirow{5}{*}{$\begin{array}{l}\text { III. Tầng } \\
\text { dày đất } \\
\text { (D) }\end{array}$} & \multirow{5}{*}{5 cấp } & 1 & $>100 \mathrm{~cm}$ \\
\hline & & 2 & $\mathrm{P}$ & & & 2 & $70-100 \mathrm{~cm}$ \\
\hline & & 3 & $\mathrm{Pf}$ & & & 3 & $50-70 \mathrm{~cm}$ \\
\hline & & 4 & Py & & & 4 & $30-50 \mathrm{~cm}$ \\
\hline & & 5 & $\mathrm{~B}, \mathrm{X}$ & & & 5 & $<30 \mathrm{~cm}$ \\
\hline & & 6 & $\mathrm{Xa}, \mathrm{Ba}$ & \multirow{4}{*}{$\begin{array}{l}\text { IV.Thành } \\
\text { phần cơ } \\
\text { giới } \\
\text { (TE) }\end{array}$} & \multirow{4}{*}{4 cấp } & $\mathrm{a}$ & Cát \\
\hline & & 7 & $\mathrm{Fa}$ & & & $\mathrm{b}$ & Cát pha \\
\hline & & 8 & $\mathrm{Fp}$ & & & $\mathrm{c}$ & Thịt nhẹ \\
\hline & & 9 & Fs & & & $\mathrm{d}$ & Thịt trung bình \\
\hline & & 10 & $\mathrm{Ha}$ & \multirow{4}{*}{$\begin{array}{l}\text { V. Đá lẫn } \\
\text { (CK) }\end{array}$} & \multirow{4}{*}{4 cấp } & 1 & Không có \\
\hline & & 11 & $\mathrm{Xk}$ & & & 2 & $<10$ \\
\hline & & 12 & $\mathrm{E}$ & & & 3 & $10-30$ \\
\hline & & & & & & 4 & $>30$ \\
\hline & & & & \multirow{3}{*}{$\begin{array}{c}\text { VI. Đá lộ } \\
\text { đầu }\end{array}$} & \multirow{3}{*}{3 cấp } & 1 & Không có \\
\hline \multirow{6}{*}{$\begin{array}{l}\text { II. Độ dốc } \\
\text { (SL) }\end{array}$} & \multirow{6}{*}{6 cấp } & 1 & $0-3^{\circ}$ & & & 2 & Rải rác \\
\hline & & 2 & $3-8^{\circ}$ & & & 3 & Tập trung \\
\hline & & 3 & $8-15^{\circ}$ & VII. Điều & \multirow{2}{*}{2 cấp } & 1 & Có tưới \\
\hline & & 4 & $15-20^{\circ}$ & kiện tưới & & 2 & Không tưới \\
\hline & & 5 & $20-25^{\circ}$ & VIII. Ngập & \multirow{2}{*}{2 cấp } & 1 & Không ngập \\
\hline & & 6 & $>25^{\circ}$ & lụt & & 2 & Có ngập \\
\hline
\end{tabular}

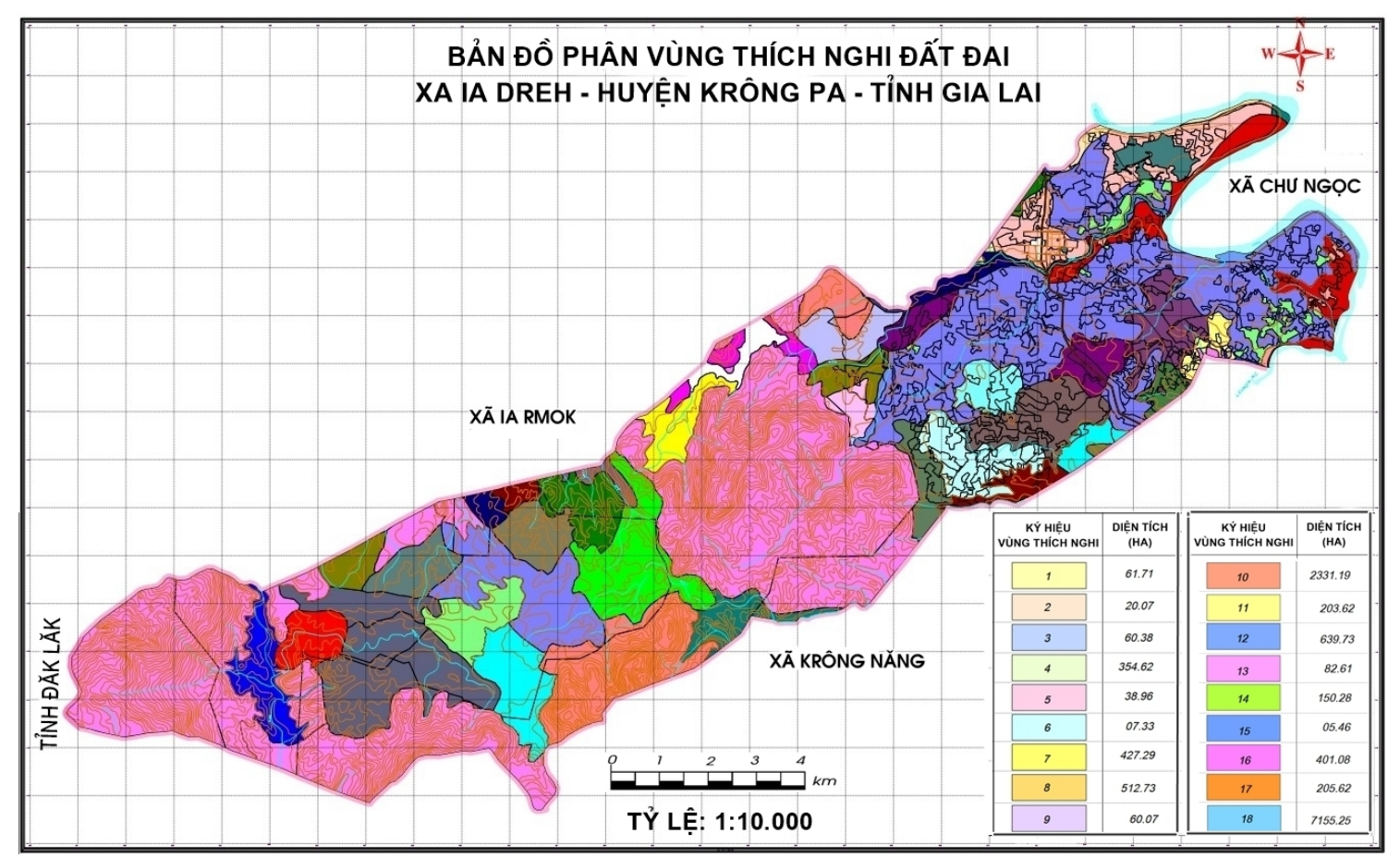

Hình 5. Bản đồ phân vùng thích nghi đất đai xã Ia Dreh, huyện Krông Pa 
Kết quả chồng xếp bản xác định được tại khu vực nghiên cứu có 52 ĐVĐĐ (LUMs), tổng hợp thành 18 vùng thích nghi, mỗi ĐVĐĐ được ký hiệu bằng số hiệu từ 1 - 52 và sắp xếp theo từng vùng đất. Trong đó, các ĐVĐĐ gồm: (a)_Vùng đất phù sa được bồi $(\mathrm{Pb})$ có 2 ĐVĐĐ, mang số hiệu 1 và 2 , diện tích 309,65 ha. ĐVĐĐ này phân bố dọc sông $\mathrm{Ba}$ và các con suối lớn, địa hình bằng phẳng, độ dốc $0-3^{\circ}$, tầng dày đất $>100 \mathrm{~cm}$, thành phần cơ giới nhẹ. Hàng năm thường hay bị ngập, ĐVĐĐ này thuận lợi cho trồng cây hoa màu; (b)_Vùng đất phù sa không được bồi $(\mathrm{P})$ có 5 ĐVĐĐ mang mã số từ 3-7 trên bản đồ, diện tích 226,51 ha, đất có độ phì khá, địa hình bằng thấp, phần lớn đã được đưa vào sử dụng trồng lúa 2 vụ; (c)_Vùng đất phù sa có tầng loang lổ đỏ vàng $(\mathrm{Pf})$ có $1 \mathrm{ĐVĐĐ}$ mang ký hiệu 8 . Độ dốc dưới $3^{\circ}$, tầng dày $>70$ $\mathrm{cm}$, có khả năng trồng hoa màu, lúa và cây công nghiệp ngắn ngày; (d)_Vùng đất phù sa ngòi suối (Py) có 3 ĐVĐĐ mang mã số từ 9-11, diện tích 235,75 ha, phân bố dọc theo các suối lớn, thường bị ngập nước. Đất có độ phì khá, khả năng phát triển trồng lúa nước; (e)_Vùng đất xám bạc màu trên đá macma acid $(\mathrm{B}, \mathrm{X})$ có 2 ĐVĐĐ mang mã số 12, 13. Diện tích 114,84 ha, thành phần cơ giới nhẹ, tầng dày từ $50-100 \mathrm{~cm}$, độ dốc $1-8^{\circ}$, chưa có tưới nước. Các ĐVĐĐ này có độ phì thấp, có khả năng trồng cây công nghiệp ngắn ngày; (f)_Vùng đất xám trên phù sa cổ $(\mathrm{Xa}, \mathrm{Ba})$ có 14 ĐVĐĐ, mang mã số từ 1427; diện tích 2980,68 ha. Phần lớn đất phân bố trên địa hình bằng phẳng có độ dốc $<3^{\circ}$, thành phần cơ giới nhẹ. Vùng đất này thích hợp với nhiều loại cây trồng trong điều kiện có tưới; (h)_Vùng đất xám trên đá macma acid $(\mathrm{Fa})$ có diện tích 2417,23 ha có 12 ĐVĐĐ, phân bố trên nhiều cấp địa hình và có tầng dày đất thay đổi rất nhiều từ mỏng đến rất dày tùy thuộc vị trí phân bố; (i)_Đất xám nâu vùng bán khô hạn (Fp) có diện tích 743,92 ha có 6 ĐVĐ đánh số từ 40-45. Đất có độ dốc từ $3-20^{\circ}$, thành phần cơ giới nhẹ, tầng dày đất thường $<70 \mathrm{~cm}$, chưa có tưới. Khó khăn cho phát triển nông nghiệp, thường thích hợp cho những cây chịu được điều kiện khắc nghiệt như mè, điều, v.v..; (j)_Vùng đất đỏ vàng trên đá phiến sét (Fs) có 3 ĐVĐĐ, phần lớn đất có độ dốc cao $>20^{\circ}$ không thích hợp cho phát triển nông nghiệp; $(\mathrm{k})$ _Vùng đất nâu thẫm trên bazan $(\mathrm{Ha})$ có 1 đơn vị đất, tầng đất mỏng $<30 \mathrm{~cm}$. (1)_Vùng đất trơ sỏi đá $(\mathrm{E})$ có 1 ĐVĐĐ mang mã số 52, diện tích 4223,77 ha, độ dốc $>15^{\circ}$, tầng đất mỏng, không có khả năng phát triển nông nghiệp.

\section{3. Đánh giá thích nghi đất đai tự nhiên}

Chồng xếp bản đồ thích nghi đất đai bền vững với bản đồ hiện trạng sử dụng đất năm 2018, tính được diện tích của các loại hình sử dụng đất và hiện trạng thích nghi đất đai khu vực nghiên cứu. Kết quả đánh giá thích nghi đất đai tự nhiên được tổng hợp và trình bày ở các Bảng 2 và Bảng 3 . Trong đó, thể hiện mức thích nghi (S) đối với các loại cây trồng khác nhau.

Việc ứng dụng GIS và hướng tiếp cận mô hình ra quyết định là công cụ có ưu thế giải quyết bài toán đa tiêu chuẩn không gian để phân tích và quản lý đất đai bền vững [7]. Kết quả đánh giá cho thấy (Bảng 3) diện tích thuộc cấp rất thích nghi (S1) chiếm tỷ lệ thấp 99,11 ha và chủ yếu thích hợp với các loại cây trồng đậu đỗ, mè và mía. Diện tích thích nghi trung bình (S2) và ít thích nghi (S2) tương đương lần lượt 19837,25 ha và 26545,8 ha. Các loại cây phù hợp với đất bao gồm đậu đỗ, mỳ, ngô, mè, điều, cây ăn quả, mía, thuốc lá. Trong khi đó, tổng diện tích đất không thích nghi $(\mathrm{N})$ chiếm tỷ lệ cao nhất với 79515,1 ha.

Dựa vào hiện trạng thích nghi đất đai đề xuất sử dụng đất cho LUTs. Kết quả diện tích các cấp thích nghi hiện tại đối với các loại hình sử dụng đất (LUTs) cho thấy cấp thích nghi S2 (trung bình), $\mathrm{S} 3$ (ít thích nghi) và $\mathrm{N}$ (không thích nghi) chiếm chủ đạo. Như vậy, ứng dụng tích hợp công cụ ALES và GIS trong đánh giá thích nghi 


\section{BÀI BÁO KHOA HỌC}

có kết quả đánh giá với độ chính xác cao và với các loại hình sử dụng đất (LUTs) được lựa thuận tiện lựa chọn các phương án thích hợp [3, chọn thể hiện chi tiết ở Hình 6 . 5]. Kết quả phân vùng thích nghi tự nhiên đối

Bảng 2. Tổng hợp mức độ thích hợp đất đai tụ nhiên

\begin{tabular}{|c|c|c|c|c|c|c|c|c|c|c|c|}
\hline \multirow[b]{2}{*}{$\begin{array}{c}\text { Mã } \\
\text { vùng }\end{array}$} & \multirow[b]{2}{*}{$\begin{array}{c}\text { Diện } \\
\text { tích (ha) }\end{array}$} & \multicolumn{10}{|c|}{ Mức độ thích nghi (S) } \\
\hline & & $\begin{array}{l}\text { Lúa } \\
\text { nước }\end{array}$ & $\begin{array}{l}\text { Lúa } \\
\text { rẫy }\end{array}$ & $\begin{array}{c}\text { Đậu } \\
\text { dô̂ }\end{array}$ & Mỳ & Ngô & Mè & Mía & $\begin{array}{c}\text { Thuốc } \\
\text { lá }\end{array}$ & Điều & $\begin{array}{l}\text { Cây } \\
\text { ăn quả }\end{array}$ \\
\hline 1 & 61,71 & S2 & $\mathrm{N}$ & $\mathrm{S} 2$ & $\mathrm{~N}$ & S2 & $\mathrm{N}$ & $\mathrm{S} 2$ & S3 & $\mathrm{N}$ & $\mathrm{N}$ \\
\hline 2 & 20,07 & S2 & S2 & S1 & S2 & $\mathrm{S} 2$ & $\mathrm{~S} 2$ & $\mathrm{~S} 1$ & S2 & $\mathrm{N}$ & S3 \\
\hline 3 & 60,38 & S3 & $\mathrm{N}$ & S2 & S3 & S2 & S2 & $\mathrm{N}$ & S2 & $\mathrm{N}$ & $\mathrm{S} 3$ \\
\hline 4 & 354,62 & S3 & $\mathrm{N}$ & S3 & S2 & S3 & $\mathrm{S} 2$ & $\mathrm{~S} 2$ & S2 & $\mathrm{S} 3$ & S3 \\
\hline 5 & 38,96 & S3 & S2 & S2 & S2 & S2 & S1 & S2 & S2 & $\mathrm{S} 2$ & S3 \\
\hline 6 & 7,33 & S3 & S3 & $\mathrm{S} 2$ & S2 & S2 & $\mathrm{S} 2$ & S2 & S2 & S2 & $\mathrm{S} 3$ \\
\hline 7 & 427,29 & $\mathrm{~N}$ & S3 & S3 & S3 & $\mathrm{S} 3$ & S2 & S3 & S3 & S3 & $\mathrm{N}$ \\
\hline 8 & 512,73 & $\mathrm{~N}$ & S3 & $\mathrm{S} 3$ & S3 & S3 & S2 & S3 & S2 & S2 & S3 \\
\hline 9 & 60,07 & $\mathrm{~N}$ & S3 & S2 & S3 & $\mathrm{S} 3$ & S2 & S3 & S3 & $\mathrm{S} 3$ & S3 \\
\hline 10 & 2331,20 & $\mathrm{~N}$ & S2 & $\mathrm{S} 3$ & S3 & S3 & S3 & $\mathrm{S} 2$ & S2 & $\mathrm{S} 2$ & $\mathrm{~S} 2$ \\
\hline 11 & 203,62 & $\mathrm{~N}$ & S2 & $\mathrm{S} 2$ & S3 & $\mathrm{S} 3$ & S2 & S2 & $\mathrm{S} 2$ & $\mathrm{~S} 2$ & S3 \\
\hline 12 & 639,73 & $\mathrm{~N}$ & $\mathrm{~N}$ & S3 & S3 & S3 & S2 & $\mathrm{S} 2+\mathrm{S} 3$ & $\mathrm{~S} 2+\mathrm{S} 3$ & S3 & S3 \\
\hline 13 & 82,61 & $\mathrm{~N}$ & $\mathrm{~N}$ & $\mathrm{~S} 3$ & $\mathrm{~N}$ & $\mathrm{~S} 3$ & $\mathrm{~N}$ & S3 & S3 & $\mathrm{N}$ & $\mathrm{N}$ \\
\hline 14 & 150,28 & $\mathrm{~N}$ & $\mathrm{~N}$ & $\mathrm{~S} 3$ & $\mathrm{~N}$ & $\mathrm{~N}$ & S3 & $\mathrm{N}$ & S3 & $\mathrm{S} 3$ & $\mathrm{~N}$ \\
\hline 15 & 5,46 & $\mathrm{~N}$ & $\mathrm{~N}$ & S3 & $\mathrm{N}$ & $\mathrm{N}$ & S3 & $\mathrm{N}$ & $\mathrm{N}$ & $\mathrm{N}$ & $\mathrm{N}$ \\
\hline 16 & 401,08 & $\mathrm{~N}$ & $\mathrm{~N}$ & $\mathrm{~S} 2$ & $\mathrm{~N}$ & $\mathrm{~S} 2$ & $\mathrm{~N}$ & $\mathrm{~S} 2$ & S3 & $\mathrm{N}$ & $\mathrm{N}$ \\
\hline 17 & 205,62 & $\mathrm{~N}$ & $\mathrm{~N}$ & $\mathrm{~S} 2$ & $\mathrm{~N}$ & $\mathrm{~N}$ & S3 & $\mathrm{N}$ & $\mathrm{N}$ & $\mathrm{N}$ & $\mathrm{N}$ \\
\hline 18 & 7155,3 & $\mathrm{~N}$ & $\mathrm{~N}$ & $\mathrm{~N}$ & $\mathrm{~N}$ & $\mathrm{~N}$ & $\mathrm{~N}$ & $\mathrm{~N}$ & $\mathrm{~N}$ & $\mathrm{~N}$ & $\mathrm{~N}$ \\
\hline
\end{tabular}

Chú thich: S1: thich nghi cao; S2: thich nghi trung bình; S3: it thich nghi; N: không thích nghi.

Bảng 3. Tổng hợp diện tích thích nghi hiện tại đối với các loại hình sủ dụng đất (LUTs)

\begin{tabular}{lcccc}
\hline \multicolumn{1}{c}{ Loại hình sử dụng đất } & \multicolumn{3}{c}{ Mức độ thích nghi } \\
\cline { 2 - 5 } \multicolumn{1}{c}{ (LUTs) } & $\mathrm{S} 1$ & $\mathrm{~S} 2$ & $\mathrm{~S} 3$ & $\mathrm{~N}$ \\
\hline LUT-1: Lúa nước & & 81,78 & 461,29 & 12174,93 \\
LUT-2: Lúa rẫy & & 379,31 & 3221,95 & 9116,74 \\
LUT-3: Đậu đô̂̀ & 20,01 & 3087,65 & 2455,03 & 7155,31 \\
LUT-4 : Mỳ & & 586,63 & 4379,01 & 7752,36 \\
LUT-5: Ngô & & 279,88 & 4921,51 & 7516,61 \\
LUT-6: Mè & 59,03 & 4624,30 & 2884,44 & 5150,23 \\
LUT-7: Điều & & 3113,90 & 1863,18 & 7740,92 \\
LUT-8: Cây ăn quả & & 116,66 & 4636,96 & 7964,38 \\
LUT-9: Mía & 20,07 & 4038,24 & 1082,70 & 7576,99 \\
LUT-10: Thuốc lá & & 3528,90 & 639,73 & 7366,63 \\
Tổng số (ha) & 99,11 & 19837,25 & 26545,80 & 79515,10 \\
\hline
\end{tabular}



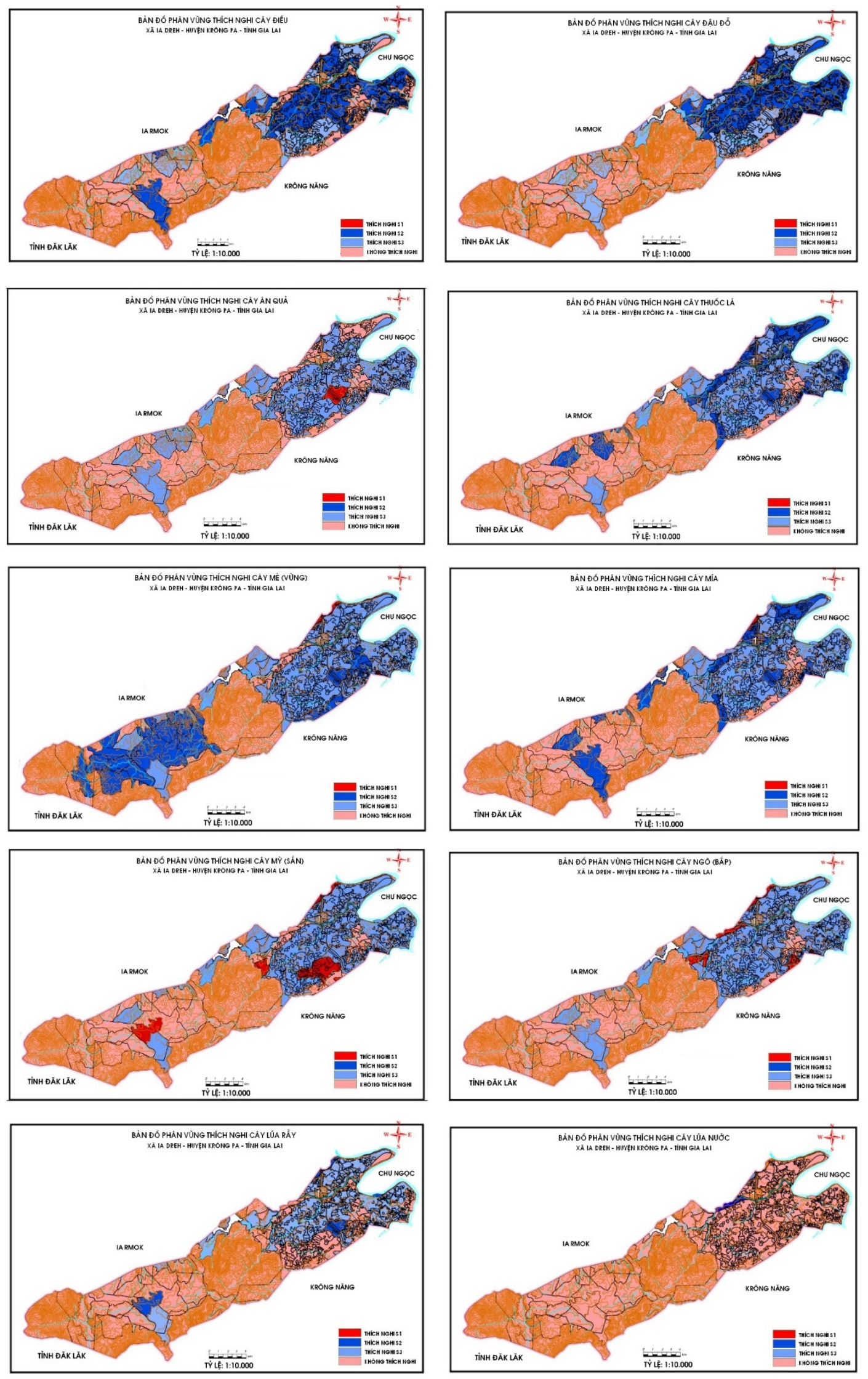

Hình 6. Bản đồ phân vùng thích nghi tụ nhiên đối với các LUTs được lựa chọn 


\subsection{Kết quả đánh giá đất đai tương lai}

Công nghệ GIS và ALES được biết đến là công cụ hữu hiệu đánh giá phát triển bền vững tài nguyên nói chung và đất đai nói riêng [9, 16-18]. Trong đánh giá đất phục vụ quy hoạch sử dụng đất đai cần phải phân hạng thích hợp các LUTs cho tương lai. Đó là sự mô tả, lựa chọn và phân hạng các LUTs trên cơ sở duy trì các LUTs hiện tại được đánh giá là bền vững, có hiệu quả hoặc thay đổi LUTs mới với các dự tính thay đổi các yêu cầu sử dụng đất hoặc các thuộc tính của các LUTs nếu có các biện pháp kỹ thuật và kinh tế - xã hội mới được áp dụng. Trên cơ sở xem xét các yếu tố hạn chế hiện tại, đánh giá phân hạng thích hợp đất đai xã Ia Dreh trong tương lai cần phải chú trọng những vấn đề về (i) cải tạo đất, (ii) kinh tế, xã hội và (iii) bảo vệ môi trường như sau [19]:

(i) Cải tạo đất: Dựa trên cơ sở yếu tố hạn chế về độ dày tầng đất (D), thành phần cơ giới (TE), đá lẫn và đá lộ đầu $(\mathrm{CK})$, điều kiện tưới tiêu kết hợp tham vấn chuyên gia cho thấy vấn đề cải tạo đất trên địa bàn xã Ia Dreh có nhiều nội dung nhưng cốt lõi là vấn đề thủy lợi. Với địa phương có lượng mưa trung bình thấp (1200 mm/năm), trong đó có 4 tháng thường xuyên khô hạn [20]. Đối với đất xã Ia Dreh nhu cầu nước tưới quan trọng bởi khi đáp ứng được nhu cầu này thì khả năng thích hợp của đất đai có thể thay đổi đột biến, làm thay đổi phương thức canh tác của cộng đồng dân tộc thiểu số. Từ đó thúc đẩy gia tăng độ màu mỡ của đất, tăng hệ số gieo trồng và tăng năng suất, sản lượng cây trồng lên đáng kể. Trong tương lai, các dự án xây dựng công trình thủy điện sông $\mathrm{Ba}$ Hạ, trạm bơm Buôn Ja Rông và hệ thống kênh mương nội đồng xây dựng hoàn thiện kết nối liên hoàn giữa hồ thủy lợi Ia Mlá, thủy lợi Ia H'Derh, nguồn nước tưới sẽ được khai thác tốt, đảm bảo đủ nước tưới cho các ĐVĐĐ, đặc biệt đối với những vùng có khả năng chuyển đổi cơ cấu và tăng vụ trong đa dạng hoá sản xuất.

(ii) Vấn đề kinh tế-xã hội: Kết quả nghiên cứu hiệu quả kinh tế đối với các loại hình sử dụng đất cho thấy các ĐVĐĐ có chất lượng cao, ít yếu tố hạn chế có khả năng bố trí các loại hình sử dụng đất với những loại cây trồng hiệu quả kinh tế cao, thu hút được nhiều lao động như lúa nước, ngô, đậu đỗ, cây điều [21]. Một số vùng đất canh tác hiệu quả kinh tế thấp, đặc biệt là những vùng trồng lúa nương rẫy có thể chuyển sang trồng các loại cây khác có hiệu quả kinh tế cao hơn [22].

(iii) Bảo vệ môi trường: Khía cạnh môi trường ở đây được xem xét trên yếu tố bảo vệ độ màu mỡ của đất, chống xói mòn và sự suy thoái, ô nhiễm đất [21]. Vì vậy hệ thống cây trồng cần phải lựa chọn theo phương châm sản xuất hiệu quả cao và an toàn về chất lượng sản phẩm. Sau khi cải tạo thủy lợi, khắc phục yếu tố hạn chế về tưới tiêu, cấp thích hợp của đất đai sẽ chuyển đổi và phù hợp với yêu cầu của các loại hình sử dụng đất. Trong tương lai Ia Dreh có khả năng chuyển một số diện tích đất từ không thích hợp sang thích hợp thấp, hoặc từ thích hợp thấp sang thích hợp cao hơn đối với một số loại hình sử dụng đất có giá trị thông qua biện pháp đầu tư xây dựng thủy lợi, hoặc chuyển đổi cơ cấu cây trồng thích nghi với điều kiện sinh thái và phù hợp với thị trường [22].

Quá trình xem xét yêu cầu của từng loại hình sử dụng đất trên các ĐVĐĐ sau khi đã cải tạo, kết quả phân hạng thích hợp tương lai đối với từng loại hình sử dụng đất được thể hiện ở Bảng 4. 
Bảng 4. Tổng hợp khả năng thich hợp đất đai tương lai tại xã Ia Dreh

\begin{tabular}{|c|c|c|c|c|c|c|c|c|c|c|c|c|}
\hline Vùng & LMUs & $\begin{array}{l}\text { Diện tích } \\
\text { (ha) }\end{array}$ & $\begin{array}{l}\text { Lúa } \\
\text { nước }\end{array}$ & $\begin{array}{l}\text { Lúa } \\
\text { rẫy }\end{array}$ & $\begin{array}{c}\text { Đậu } \\
\text { đỗ }\end{array}$ & Mỳ & Ngô & Mè & Mía & $\begin{array}{c}\text { Thuốc } \\
\text { lá }\end{array}$ & Điều & $\begin{array}{l}\text { Cây } \\
\text { ăn } \\
\text { quả }\end{array}$ \\
\hline 1 & 9 & 61,71 & S1 & $\mathrm{N}$ & $\mathrm{S} 2$ & $\mathrm{~N}$ & S2 & $\mathrm{N}$ & $\mathrm{N}$ & $\mathrm{N}$ & S2 & S3 \\
\hline 2 & 4,8 & 20,07 & S1 & S1 & $\mathrm{S} 1$ & S1 & $S 1$ & S1 & $S 2$ & $\mathrm{~N}$ & S1 & S1 \\
\hline 3 & 19,20 & 60,38 & S3 & $\mathrm{N}$ & $S 2$ & S3 & S1 & S2 & $S 2$ & $\mathrm{~N}$ & $S 3$ & $\mathrm{~S} 2$ \\
\hline 4 & 28,31 & 354,62 & $S 2$ & $\mathrm{~N}$ & $\mathrm{~S} 3$ & S2 & S3 & S1 & S3 & S3 & $S 1$ & $\mathrm{~S} 2$ \\
\hline 5 & 5 & 38,96 & S1 & S1 & S1 & $\mathrm{S} 2$ & S1 & S1 & $S 2$ & S1 & S1 & $\mathrm{S} 2$ \\
\hline 6 & 23 & 7,33 & S3 & $S 2$ & $\mathrm{~S} 2$ & $\mathrm{~S} 2$ & $\mathrm{~S} 2$ & S1 & S3 & $\mathrm{S} 2$ & $S 1$ & S2 \\
\hline 7 & 24,25 & 427,29 & $\mathrm{~N}$ & $S 2$ & $\mathrm{~S} 3$ & $\mathrm{~S} 3$ & $\mathrm{~S} 3$ & $S 2$ & $\mathrm{~N}$ & $S 2$ & S3 & $S 2$ \\
\hline 8 & $\begin{array}{l}40,41,42, \\
43\end{array}$ & 512,73 & $\mathrm{~N}$ & S3 & S3 & S3 & $S 2$ & S2 & $\mathrm{S} 3$ & $\mathrm{~S} 2$ & S3 & S2 \\
\hline 9 & 16,17 & 60,07 & $\mathrm{~N}$ & $\mathrm{~S} 3$ & S1 & $\mathrm{S} 3$ & $\mathrm{~S} 3$ & $S 2$ & S3 & $\mathrm{S} 3$ & $\mathrm{~S} 3$ & S3 \\
\hline 10 & $\begin{array}{l}14,15,18,21 \\
27,46\end{array}$ & 2331,19 & $\mathrm{~N}$ & $S 2$ & $\mathrm{~S} 3$ & $\mathrm{~S} 3$ & $\mathrm{~S} 3$ & $\mathrm{~S} 3$ & S2 & $\mathrm{S} 2$ & $\mathrm{~S} 2$ & $S 1$ \\
\hline 11 & 3,50 & 203,62 & $\mathrm{~N}$ & $S 2$ & $\mathrm{~S} 2$ & $\mathrm{~S} 3$ & $\mathrm{~S} 3$ & S2 & S3 & S1 & $\mathrm{S} 2$ & S1 \\
\hline 12 & $\begin{array}{c}13,29,30 \\
32,34,36\end{array}$ & 639,73 & $\mathrm{~N}$ & $S 3$ & S3 & S3 & S3 & $S 2$ & S3 & S3 & S2 & S2 \\
\hline 13 & 10 & 82,61 & $\mathrm{~N}$ & $\mathrm{~N}$ & S3 & $\mathrm{N}$ & S3 & $\mathrm{N}$ & $\mathrm{N}$ & $\mathrm{N}$ & S3 & S3 \\
\hline 14 & 12,35 & 150,28 & $\mathrm{~N}$ & $S 3$ & S3 & $\mathrm{N}$ & $\mathrm{N}$ & S3 & $\mathrm{N}$ & S3 & $\mathrm{N}$ & S3 \\
\hline 15 & 26 & 5,46 & $\mathrm{~N}$ & $\mathrm{~N}$ & S3 & $\mathrm{N}$ & $\mathrm{N}$ & S3 & $\mathrm{N}$ & $\mathrm{N}$ & $\mathrm{N}$ & $\mathrm{N}$ \\
\hline 16 & $1,2,11$ & 401,08 & $\mathrm{~N}$ & $\mathrm{~N}$ & $S 2$ & $\mathrm{~N}$ & $\mathrm{~S} 2$ & $\mathrm{~N}$ & $\mathrm{~N}$ & $\mathrm{~N}$ & S1 & S3 \\
\hline 17 & 22 & 205,62 & $\mathrm{~N}$ & $\mathrm{~N}$ & $S 2$ & $\mathrm{~N}$ & $\mathrm{~N}$ & $\mathrm{~S} 3$ & $\mathrm{~N}$ & $\mathrm{~N}$ & $\mathrm{~N}$ & $\mathrm{~N}$ \\
\hline 18 & $\begin{array}{l}6,7,33,37,38 \\
39,44,45,47 \\
48,49,51,52\end{array}$ & 7155,25 & $\mathrm{~N}$ & $\mathrm{~N}$ & $\mathrm{~N}$ & $\mathrm{~N}$ & $\mathrm{~N}$ & $\mathrm{~N}$ & $\mathrm{~N}$ & $\mathrm{~N}$ & $\mathrm{~N}$ & $\mathrm{~N}$ \\
\hline & Tổng & \multicolumn{11}{|c|}{12718,06} \\
\hline
\end{tabular}

Chú thich: S1: thich nghi cao; S2: thich nghi trung bình; S3: it thich nghi; N: không thich nghi.

\section{5. Định hướng quy hoạch sử dụng đất}

Nhìn chung, phương pháp đánh giá đa tiêu chí như kinh tế, xã hội và môi trường có vai trò quan trọng chỉ ra các kiểu sử dụng đất đai phù hợp với từng nhóm đối tượng [23-24]. Trên cơ sở tiềm năng đất nông nghiệp và đánh giá thích nghi đất đai tương lai đối với các loại hình sử dụng đất chính, nghiên cứu đề xuất quy mô sử các loại hình sử dụng đất nông nghiệp (LUTs) xã Ia Dreh phục vụ quy hoạch sử dụng đất như sau: LUT-1 (Lúa nước 2 vụ): Diện tích thích nghi $\mathrm{S} 1, \mathrm{~S} 2$ là 475,36 ha. Diện tích đề xuất là 120 ha, bố trí trên các ĐVĐĐ số 4, 5, 8, 9. LUT-2 (Lúa rẫy): Diện tích thích nghi 3601,26 ha. Diện tích đề nghị chuyển đổi 2615,00 ha sang trồng điều, cây ăn quả và hoa màu. Diện tích lúa rẫy còn lại đề xuất chuyển đổi sang mô hình Lúa màu. LUT-3 (Đậu đỗ): Diện tích thích nghi 5562,69 ha, diện tích đề xuất 339 ha, bố trí trên các ĐVĐĐ số 16, 17, 19, 20, 22, 26. LUT-4 (Mỳ): Diện tích thích nghi 4965,64 ha, diện tích đề xuất 355 ha, bố trí trên các ĐVĐĐ số 28,31 . LUT-5 (Ngô): Diện tích thích nghi 5201,39 ha, diện tích đề xuất 512,73 ha, bố trí trên các ĐVĐĐ số 40, 41, 42, 43. LUT-6 (Mè): Diện tích thích nghi 7567,77ha, diện tích đề xuất 1067 ha, bố trí trên các ĐVĐĐ số 13, 24, 25, 29, 30, 32, 34, 36. LUT-7 (Điều): Diện tích thích nghi 4977,08 ha, diện tích đề xuất 400 ha, bố trí trên các ĐVĐĐ số 1, 2, 11. LUT-8 (Cây ăn quả): Diện tích thích nghi 4753,62 ha. Cây ăn quả được bố trí trên các vùng thích nghi $\mathrm{S} 2, \mathrm{~S} 3$ của các ĐVĐĐ số $10,12,35$, diện tích đề xuất 233 ha. LUT-9 (Mía): Diện tích thích nghi 5141,01 ha. Diện tích đề xuất 2331 ha, bố trí trên các ĐVĐĐ số 14, 15, 18, 21, 27, 46. LUT-10 (Thuốc lá): Được bố trí trên các vùng thích nghi $\mathrm{S} 1, \mathrm{~S} 2$ với diện tích 203 ha, bố trí trên các ĐVĐĐ số 3, 50. Như vậy, kết quả định hướng sử dụng đất xã Ia Dreh sẽ góp phần hữu ích trong quá trình quy hoạch nông nghiệp địa phương theo hướng phát triển bền vững. 


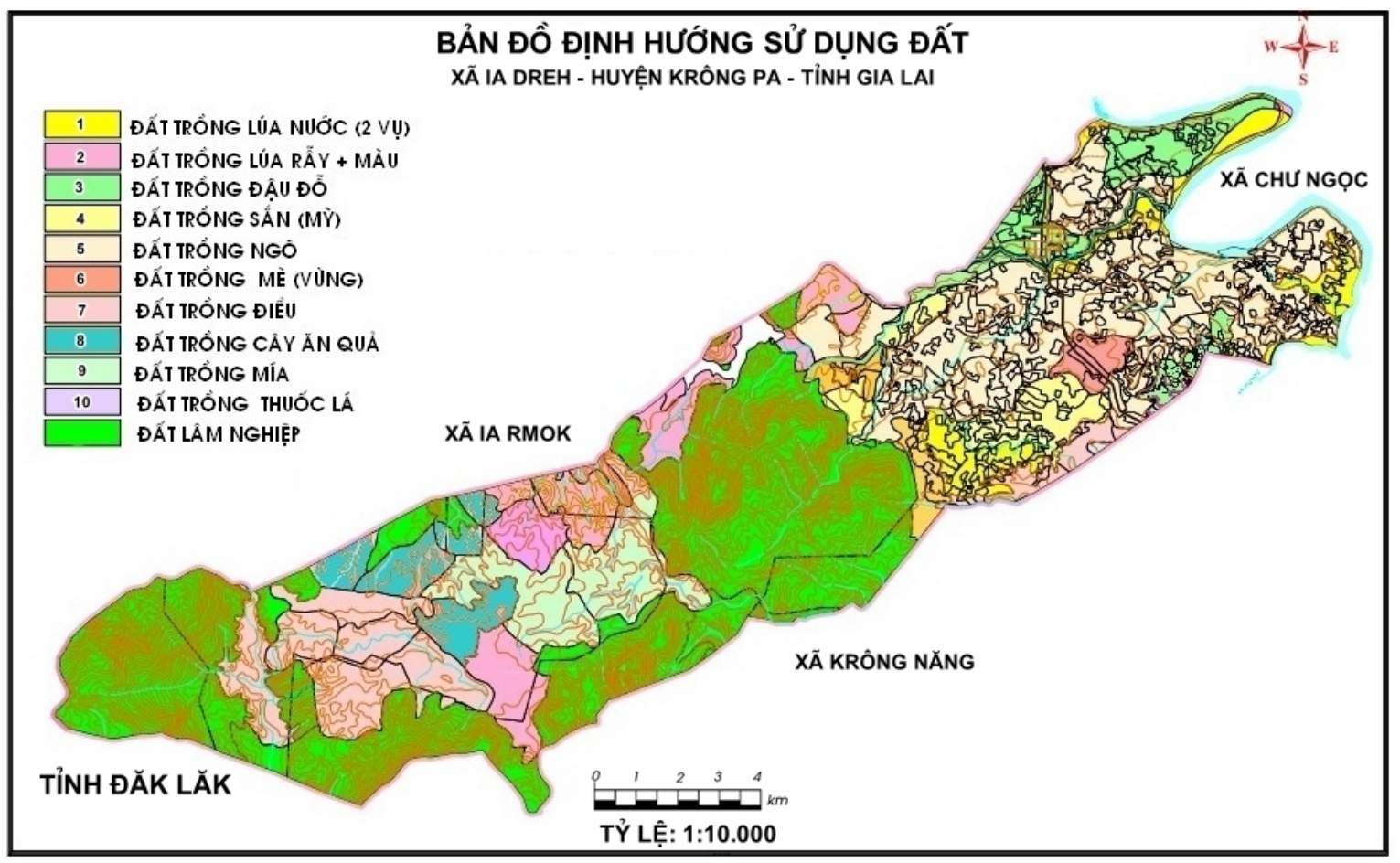

Hình 7. Bản đồ định hướng sử dụng đất xã Ia Dreh

\section{Kết luận và khuyến nghị}

Kết quả đánh giá thích nghi đất đai đối với các loại cây trồng bằng mô hình tích hợp ALES - GIS đã xác định được 52 ĐVĐĐ với 18 vùng thích nghi đất đai. Trong đó, diện tích rất thích nghi 99,11 ha (chiếm 0,08\%); thích nghi trung bình 19837,25 ha (chiếm 15,74\%); ít thích nghi 26545,80 ha (chiếm 21,07\%) và không thích nghi 79515,10 ha (chiếm 63,11\%). Kết quả đánh giá thích nghi phục vụ cho định hướng quy hoạch sử dụng đất nói chung và xây dựng vùng nguyên liệu cho sản xuất nông nghiệp trên địa bàn xã nói riêng. Bên cạnh việc phân tích được tính bền vững trong canh tác nông nghiệp về mặt cải tạo đất, xã hội và môi trường theo thứ tự ưu tiên của các kiểu sử dụng đất là lúa nước, ngô, mỳ, mía, thuốc lá (yếu tố bền vững về xã hội); điều và cây ăn quả (yếu tố bền vững về môi trường), đậu đỗ, mè (yếu tố cải tạo đất). Nghiên cứu cho thấy kết quả đầu ra chính xác và có tính hiện thực cao. Úng dụng mô hình vào đánh giá thích nghi đất đai sẽ tiết kiệm thời gian, nâng cao năng suất lao động. Trong thời gian tới, có thể nhân rộng mô hình này cho đánh giá đất đai ở các địa phương khác trong tỉnh. Sự tích hợp GIS - ALES góp phần quan trọng giải quyết bài toán quyết định đa tiêu chuẩn không gian lựa chọn vùng thích nghi cho các loại cây trồng. Quá trình đánh giá có sự tham gia của các đối tượng quản lý và sử dụng đất trên địa bàn do đó kết quả sử dụng đất bền vững phù hợp với thực tiễn của địa phương. Tuy nhiên, hạn chế của nghiên cứu chưa xem xét, đánh giá chuyên sâu yếu tố khí tượng thủy văn trong quá trình định hướng quy hoạch sử dụng đất. Do đó trong tương lai cần quan tâm nghiên cứu, bổ sung khía cạnh này nhằm đề ra những khuyến cáo thích hợp trong bối cảnh biến đổi khí hậu toàn cầu. 


\section{Tài liệu tham khảo}

1. FAO (1976), A framework for land evaluation, Soils Bulletin 32, Rome, Italy.

2. FAO (1993), An international Framework for Evaluating Sustainable Land Management (FESLM), Rome, Italy.

3. Hoàng Thị Huyền Ngọc, Nguyễn Đình Kỳ, Lưu Thế Anh (2013), Úng dụng mô hình tích hơp ALES - GIS đánh giá thích nghi đất đai phục vu phát triển cây chè khu vực Di Linh - Bảo Lộc. Tạp chí Các Khoa học về Trái đất, 35(3), 272-279.

4. Rossiter, D.G., Armand, R.V.W., (2000), Automated Land Evaluation System (ALES) Version 4.65 User's Manual, Cornell university, USA.

5. Nguyễn Cao Huần, Nguyền An Thịnh, Phạm Quang Tuấn (2004), Mô hình tích hợp ALES-GIS trong quá trình đánh giá cảnh quan phục vu phát triển cây trồng nông, lâm nghiệp huyện Sa Pa tỉnh Lào Cai. Tạp chí Khoa học ĐHQG Hà Nội, 4, 43-50.

6. Lê Cảnh Định (2007), Tích hợp ALES và GIS trong đánh giá thích nghi đất đai huyện Cẩm Mỹ - tỉnh Đồng Nai, Tạp chí Khoa học kỹ thuật Nông Lâm nghiệp, 2, 206-213.

7. Ali, M., Mahmoud, M.S., Biswajeet, P., Fatma, A. (2009), Utilization of remote sensing data and GIS tools for and use sustainability analysis: case study in El-Hammam area, Egypt. Central European Journal of Geosciences, 1 (3), 347-367.

8. El-Kawy, O.R.A., Ismail, H.A., Rød, J.K., Suliman, A.S. (2010), A Developed GIS-based Land Evaluation Model for Agricultural Land Suitability Assessments in Arid and Semi Arid Regions. Research Journal of Agriculture and Biological Sciences, 6 (5), 589-599.

9. Mohamed, S.G., El-Baroudy, A.A., Ibrahim, M.M., Mohamed, E.S. (2018), GIS-based for land evaluation in some areas at West of Nile delta, Soil Science and Agricultural Engineering, 45 (4), 1309-1319.

10. Calys-Tagoe, E., Sadick, A., Asamoah, G., Alema, M. (2019), GIS-based Analysis of Indigenous and Technical Knowledge of Soil Suitability Evaluation of Cocoa, Citrus and Oil Palm in Ejisu-Juabeng District, Ashanti Region, Ghana, International Journal of Plant \& Soil Science, 29 (2), $1-8$.

11. Worldbank (2018), Vietnam - Renewable Energy Development Project: Environmental plan (Vol. 11): Environmental management plan for Krong PA 2 Small Hydro Power Project, Gia Lai province.

12. Phan Chí Nguyện, Phạm Văn Hiệp, Trần Văn Dũng, Phạm Thanh Vũ và Nguyễn Kim Lợi (2017), Đánh giá tiềm năng đất đai phục vu cho sản xuất nông nghiệp ở huyện Cai Lậy, tỉnh Tiền Giang. Tạp chí Khoa học, Đại học Cần Thơ, 2, 55-65.

13. Matthew, J.S. (1999), The use of GIS in recreation planning: An application of spatial analysis to find suitable location for recreational, Proceedings of the 1999 Northeastern Recreation Research Symposium, Department of Agriculture, Forest Service, Northeastern Research Station, NY, pp. 391-396.

14. David, G.R., Armand, R.V.W. (1997), Automated Land Evaluation System ALES Version 4.65 User's Manual, Cornell University.

15. Ahn, C.W., Baumgardner, M.F., Biehl, L.L. (1999), Delineation of soil variability using geostatistics and fuzzy clustering analysis of hyperspectral data. Soil Science of American Journal, 63 (1), 142-150.

16. Ismail, H.A., Morsy, I.M., El-Zahaby, E.M., El-Nagar F.S. (2001), A Developed expert system for land use planting by coupling and modeling. Alexandria Journal of Agricultural Research, 46 (3), 141-154. 


\section{BÀI BÁO KHOA HỌC}

17. Zhang, H., Shata, A.A.A.S., El-Sawey, Abdel-Hameed, A., Schroder, J.L. (2011), Land suitability classification of a desert area in Egypt for some crops using Microleis program. AmericanEurasian Journal of Agricultural and Environmental Sciences, 8 (1), 80-94.

18. Nguyễn Thị Lan Thương, Nguyễn Minh Kỳ (2019), Ứng dụng GIS đánh giá biến động diện tích đất lâm nghiệp huyện K’bang, tỉnh Gia Lai và đề xuất giải pháp quản lý bền vũng. Kỷ yếu Hội thảo Úng dụng GIS toàn quốc năm 2019, NXB Nông nghiệp, 486-495.

19. Võ Thị Phương Thủy, Lê Cảnh Định, Phạm Nguyễn Kim Tuyến, Nguyễn Hiếu Trung (2011), Tích hợp GIS và phân tích đa tiêu chuẩn (MCA) trong đánh giá thich nghi đất đai. Kỷ yếu hội thảo ứng dụng GIS toàn quốc năm 2011, 165-174.

20. UBND huyện Krông Pa (2011), Quy hoạch sủ dụng đất đến năm 2020, kế hoạch sư dụng đất kỳ đầu (2011-2015) huyện Krông Pa, Gia Lai.

21. UBND huyện Krông Pa (2014), Quy hoạch sủ dụng đất đến năm 2020, kế hoạch sủ dụng đất kỳ đầu (2011-2015) xã Ia Dreh, huyện Krông Pa, Gia Lai.

22. UBND xã Ia Dreh (2011), Quy hoạch xây dụng nông thôn mới xã Ia Dreh giai đoạn 20112020, Krông Pa.

23. Reshmidevi, T.V., Eldho, T.I., Jana, R. (2009), A GIS-integrated fuzzy rule-based inference system for land suitability evaluation in agricultural watersheds. Agricultural Systems, 101 (1-2), 101-109.

24. Lê Quang Trí, Phạm Thanh Vũ (2011), Úng dụng công nghệ thông tin trong đánh giá đất đai tự nhiên và đánh giá thích nghi đa tiêu chí ở huyện Càng Long, tỉnh Trà Vinh. Tạp chí Khoa học, Đại học Cần Thơ, 18B, 63-72.

\section{INTEGRATION OF GIS AND ALES TECHNIQUES FOR AGRICUL- TURAL LAND SUITABILITY EVALUATION TO SUPPORT COMMUNE-LEVEL LAND USE PLANNING - CASE STUDY IN GIA LAI PROVINCE Nguyen Ninh Hai ${ }^{1}$, Nguyen Tuan Anh ${ }^{1}$, Nguyen Thi Nhu Huong², Bach Quang Dung ${ }^{3}$, Nguyen Minh $\mathrm{Ky}^{\mathbf{1}^{*}}$ \\ ${ }^{1}$ Nong Lam University of Ho Chi Minh City, Vietnam ${ }^{2}$ Pleiku High School, Gia Lai Province, Vietnam}

${ }^{3}$ Viet Nam Meteorological and Hydrometeorological Administration, Ha Noi, Vietnam

Abstract: The study presents the results of the integrated model of ALES and GIS techniques in agricultural land suitability evaluation for commune-level land use planning - a typical case of Ia Dreh commune, Krong Pa district, Gia Lai Province. The research was obtained the crucial information of natural condition, sector of economic, society and environment by used Participatory Rural Appraisal method (PRA) combine with material resources. In addition, approach based on FAO's land evaluation methodology was used to land suitability evaluation for economic and society of commune, towards sustainable land use. The results showed that with the land characteristics, 52 land units (LUMs) have been established for 10 land use types (paddy rice, upland rice, beans, wheat, sesame maize, cashew, fruit trees, sugarcane and tobacco), aggregated into 18 adaptable regions. Based on the land adaptation of natural and economic conditions as well as the impact of social and environmental factors, the proposed sustainable land use models. Thereby, as a basis for planning appropriate land use, effective, which meet the needs of sustainable development in the study area.

Keywords: Land suitability, ALES - GIS, Ia Dreh, Krong Pa, Land use planning, Environment. 